\title{
CAPACITY UTILIZATION IN NEPALESE SUGAR INDUSTRY
}

\author{
Sadan Kumar Bhagat*
}

\begin{abstract}
Under utilization of production capacity is a common issue for Nepalese manufacturing enterprises and sugar industry is no exception to this. This study mainly deals with the cause of underutilization of production capacity of Nepalese sugar mills as well as the market situation of sugar and sugarcane. In spite of sufficient production of sugarcane, the sugar mills do not get adequate quantity and proper quality of sugarcane at right time. Almost half of the sugarcane production has no market which reveals the poor procurement system. The approved production capacity of Nepalese sugar mills is more than domestic requirement of sugar. However, the unfulfilled demand for sugar is fulfilled mainly by imported as well as smuggled Indian sugar. The capacity utilization rate of Nepalese sugar industry, which has been decreasing, dropped to 45 percent in FY 2008/09. The main identified reasons are stoppage, breakdown and slow motion of machines, delay in settlement of minimum support price of sugarcane and late commencement of production season, political instability, less operation days of sugar mills and ultimately the overlook of sugar producers to utilize their full capacity of production. Measures to improve the capacity utilization rate of sugar mills have become an urgent need.
\end{abstract}

\section{INTRODUCTION}

Nepal is an agricultural country where majority of people live in rural areas and most of them are dependent on agriculture. Agro-based industries are prominent in Nepal. So with the establishment of various sugar mills, the economic as well as social condition of sugarcane growing farmers have improved significantly. On the other hand, in the case of sugar production Nepal has been moving on the path of self-sufficiency. However, the domestic production of sugar has not yet been sufficient to meet the growing demand of sugar. The approved production capacity of Nepalese sugar mills is more than estimated demand but the actual production is less than national demand. Inadequate supply of sugar is met by imported as well as smuggled sugar from India. There is no denial that one of the major problems of Nepalese sugar mills is under utilization of production capacity. On the basis of increasing population, approximately 161800 MT sugar is needed annually in Nepal. A conservative estimate is that Nepalese people consume sugar @ $6 \mathrm{~kg}$. per head so the total requirement of sugar was 161800 MT in FY 2008/09 (on the basis of estimated population 26966581). If the prevailing sugar mills operated with full capacity, almost 200000 MT sugar could be produced. Surplus sugar could rather be exported. Unfortunately, sugar mills are operating below the production capacity and Nepalese sugar mills have utilized only half of their production capacity on 
average. The production capacity of sugar mills has increased but production of sugar could not increase at the same rate.

Nepalese sugar mills do not run at full capacity and low production of sugar has created scarcity in the market causing adverse effect on the demand and supply of sugar. Consequently, the price of sugar increases every year immensely. Sugar is imported from abroad at high cost. Almost one thousand eight hindered eighty $\mathrm{km}$. long open Indo-Nepal border has made easy for smugglers to sell sugar from India into Nepalese market. The demand for sugar in border area was fulfilled by smuggled sugar (Bhagat 2008).

There is ample production of sugarcane in Nepal and it is sufficient to fulfill the need of sugar mills. Even if all sugar mills run in full capacity, they cannot crush all sugarcane. Sugar mills are operating below the capacity and they crush only about 50 percent sugarcane produced by Nepalese farmers. The remaining sugarcane has no market. However, the quality of Nepalese sugarcane is not as good as the sugarcane of Uttar Pradesh and Bihar State (India) which is suitable for sugar production and the recovery rate is higher in comparison to Nepalese sugarcane.

According to the data of Ministry of Agriculture and Co-operatives 2599789 MT sugarcane was grown in Nepal in FY 2006/07 which was 5.57 percent higher than previous year's sugarcane production. In spite of these facts, Nepalese sugar mills consumed only 1148712 MT sugarcane to produce 103384 MT sugar (9 percent recovery) and the rest 1451077 MT sugarcane was not purchased by Nepalese sugar mills. Thus, there was no market for such sugarcane. The farmers, who are living far from the command area of sugar mills, cannot supply their produce to Nepalese sugar mills. In this situation, either they produce gur/sakkhar themselves or they sell their produce to the nearest Khandsari mills at lower rate. In the absence of Khandsari mills, they sell to Indian sugar mills illegally, especially the farmers who are living near the open Indo-Nepal border.

\section{OBJECTIVES}

The main objectives of this study are to comprehend the capacity utilization rate of medium and large-scale sugar mills of Nepal, to analyze the reasons of under utilization of production capacity and to suggest appropriate measures to increase the capacity utilization rate.

\section{METHODOLOGY}

Eleven medium and large-scale sugar mills are registered in Nepal. These sugar mills are closed now and eight sugar mills are in operation which are as follows:

I. Indu Shankar Chini Udyog Ltd., Hariwan, Sarlahi.

II. Lumbinin Sugar Mills Pvt. Ltd., Sunwal, Nawalparsi.

III. Mahalaxmi Sugars Limited, Jawabhari, Kapilbastu.

IV. $\quad$ Sri Ram Sugar Mills Ltd., Garuda, Rautahat.

V. $\quad$ Everest Sugar and Chemical Industries Ltd., Ramnagar, Mahottari.

VI. Vasulinga (DSM) Sugar Mills Ltd., Chuha, Kailali.

VII. Eastern Sugar Mills Ltd., Yamahi Belha, Sunsari.

VIII. Bagmati Khandsari Sugar Industries, Pvt. Ltd., Kudai, Nawalparasi. 
To comprehend the situation, the production data of four sugar mills are collected for the purpose of study. The selected four operating sugar mills are as follows:

I. Indu Shakare Chini Udyoug Ltd., Hariwan, Sarlahi

II. Lumbinin Sugar Mills Pvt. Ltd., Sunwal, Nawalparsi

III. Sri Ram Sugar Mills Ltd., Garuda, Rautahat

IV. Everest Sugar and Chemical Industries Ltd., Ramnagar, Mahottari.

The production data of above mentioned four sugar mills are analyzed from FY 1995/96 to FY 2001/02. The data is collected by the researcher during pursuing his doctoral research entitled 'Marketing of Agro-Based Products in Nepal (with special reference to cigarette and sugar)'. However, the country level data of sugar production are analyzed and examined from FY 1995/96 to FY 2008/09 to understand the phenomenon in better way. Khandsari mills (small and conventional sugar production plant) have been excluded in this study as they are very small, working irregularly and production data of those Khandsari mills are not available. The collected data are presented in tables and analyzed to draw inference. The analysis of this study is based on field survey, unpublished official records and reports of sugar mills and secondary data provided by selected sugar mills as well as published data of various publications.

\section{IMPLICATIONS OF CAPACITY UTILIZATION}

Optimum utilization of installed capacity is the foundation stone of rapid industrialization and economic growth with higher productivity in the enterprises. The level of industrial capacity utilization has direct and substantial effect on the pattern of industrial employment in the country. Greater the utilization of capacity higher will be the output and the rate of employment. It has an important implication especially for the country like Nepal because it helps to generate employment opportunities (Shrestha 2004). By improving the level of capacity utilization, the growth rate of economy as a whole can be revised (Pradhan 1980).

The progress of an economy is indicated not by how much it produces but how efficiently it produces. It is the outcome of optimum utilization of installed capacity. Capacity utilization is the vital aspect of the enterprises and basis of their productivity (Srivastava 1982). It is a tool of measuring industrial efficiency. The major aspects of the performance of the industry related to the capacity utilization (Industrial Times 1976). However, this is the most neglected aspect in Nepalese manufacturing organizations and sugar industry is no exception to this case. Obviously, the level of industrial capacity must be utilized to the maximum extent so that the cost of output can be minimized through the spread of fixed cost.

Various studies of Nepalese manufacturing enterprises, especially cigarette and sugar factories, revealed that low capacity utilization was the major cause of loss (Bajracharya and Shrestha 1983, Das 1989, Mahto 2003, Mishra 2001, Pandey 2003, Regmi 2003, Sah 1997, Sharma 1999 and Subedi 1978). Bista's study (1985) examined various causes of under utilization of organization's capacity. He found that lack of raw material was major reason in capacity of sugar (Subedi 1978). In spite of increase in sugarcane production, yield and sugarcane growing area, Sri Ram Sugar Mills Ltd. Garuda could not utilize its optimum capacity of production due to non-availability of sufficient 
raw material (sugarcane) at right quantity, at right time and at the right place (Regmi 2003). Similarly, the deviation in capacity utilization of Birgunj Sugar Factory Limited and Indushankar Chini Udyog Ltd. was mainly due to fluctuation of cane availability (Sah 1997). Another facet of low capacity utilization of manufacturing enterprises was small size of domestic market and less opportunity to penetrate in foreign market (Sharma 1999).

\section{TRENDS IN CAPACITY UTILIZATION IN NEPALESE SUGAR INDUSTRY}

There are two types of sugar manufacturing units in Nepal. One is large and medium scale sugar mills and other is Khandsari mills. Khandsari mills use conventional system of sugar production whose contribution is less than 5 percent in domestic production of sugar. The operation of Khandsari mills is not regular and the number of Khandsari mills have been decreasing every year. It is costly to operate and the recovery percentage of sugar from sugarcane in Khandsari mills is very low, which discourage entrepreneur to continue the operation.

The second type of sugar manufacturing unit is medium and large-scale sugar mills. Out of eight operating sugar mills, only three are large and regular in production. The contribution of Indu Shankar Chini Udyog Ltd., Hariwan, Sri Ram Sugar Mills Ltd., Garuda, and Everest Sugar and Chemical Industries Ltd., Ramnagar is more than 50 percent in domestic production of sugar. However, most of the Nepalese sugar mills are not in a position to utilize their full capacity due to various factors. Table No. 1 reveals capacity utilization rate and number of operation days of some major and selected sugar mills of Nepal from Fiscal Year 1995/96 to FY 2001/02. The information provided in Table 1, was collected by the author (researcher) during pursuing his doctoral research.

Table 1. Capacity Utilization and Number of Operation Days of Some Major and Selected Sugar Mills of Nepal from Fiscal Year

1995/96 to FY 2001/02

Capacity Utilization in Percentage

\begin{tabular}{|c|c|c|c|c|c|c|c|c|}
\hline \multirow[b]{2}{*}{$\begin{array}{l}\text { Fiscal } \\
\text { Years }\end{array}$} & \multicolumn{2}{|c|}{$\begin{array}{l}\text { Lumbini Sugar } \\
\text { Mills Ltd. }\end{array}$} & \multicolumn{2}{|c|}{$\begin{array}{l}\text { Sri Ram Sugar } \\
\text { Mills Ltd. }\end{array}$} & \multicolumn{2}{|c|}{$\begin{array}{c}\text { Everest Sugar } \\
\text { and Chemical } \\
\text { Ind. Ltd. }\end{array}$} & \multicolumn{2}{|c|}{$\begin{array}{c}\text { Indu Shankar } \\
\text { Chini Udyog } \\
\text { Ltd. }\end{array}$} \\
\hline & 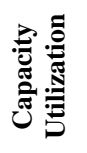 & 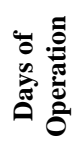 & 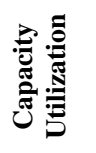 & 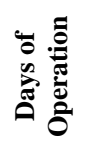 & 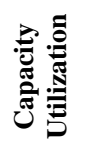 & 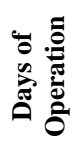 & 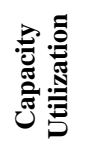 & 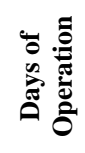 \\
\hline $1995 / 96$ & 117.53 & 151 & 120.41 & 163 & - & - & 141.69 & 190 \\
\hline $1996 / 97$ & 114.78 & 153 & 67.23 & 138 & 58.42 & 115 & 131.10 & 149 \\
\hline $1997 / 98$ & 86.85 & 120 & 62.96 & 117 & 60.55 & 95 & 83.70 & 93 \\
\hline $1998 / 99$ & 61.95 & 84 & 62.43 & 106 & 61.44 & 105 & 104.52 & 101 \\
\hline $1999 / 2000$ & 83.40 & 101 & 77.67 & 158 & 98.52 & 139 & 85.72 & 151 \\
\hline $2000 / 2001$ & 51.27 & 74 & 56.71 & 118 & 45.78 & 104 & 73.67 & 114 \\
\hline $2001 / 2002$ & 60.70 & 98 & 53.32 & 105 & 41.99 & 79 & 67.73 & 95 \\
\hline
\end{tabular}

Source: Sadan Kumar Bhagat (2008), Unpublished Ph.D. Dissertation, p. 156

Normally 120 days' production of sugar is considered standard for large and medium scale sugar mills. Lumbini Sugar Mills Ltd., Sunwal operated more 
than standard operation days during the season of production in FY 1995/96 and FY 1996/97, so its capacity utilization rate was high. Since FY 1998/99 the capacity utilization rate fell down and it could not utilize full capacity of production till FY 2001/02 because the mill operated less than standard operation days during these periods.

The capacity utilization rate was satisfactory i.e. 120.41 percent in Sri Ram Sugar Mills Ltd., Garuda in FY 1995/96 because it operated for 163 days. In FY 1996/97 and FY 1999/2000 mill operated for 138 days and 158 days but the capacity utilization rate was 67.23 percent and 77.67 percent only respectively. Though operated for long period it could not achieve higher productivity. The identified reasons were that the speed of production was slow and during later days of production, the mills got mostly dry sugarcane which contained lesser sucrose. As a result, the recovery percentage of sugar from sugarcane dropped which ultimately influenced the production quantity adversely.

Everest Sugar and Chemical Industries Ltd., Ramnagar could not show good capacity utilization rate except in FY 1999/2000 when it was 98.52 percent. Except this fiscal year, its capacity utilization rate prevailed between 42 percent and 61 percent only till FY 2001/02.

In Indu Shankar Chini Udyog Ltd., Hriwan the capacity utilization rate was 141.69 percent 31.10 percent and 104.52 percent and the days of operation was 190 days, 149 days and 101 days during FY 1995/96, FY 1996/97 and FY 1998/99 respectively. During these fiscal years, the mill operated for long period so the capacity utilization rate was more than 100 percent. It spite of prolonged crushing period (151 days), it could not achieve satisfactory rate of capacity utilization in FY 1999/2000 as it was 85.72 percent only. The mills operated for 114 days and 95 days in FY 2000/2001 and FY 2001/2002 and it utilized only 73.67 percent and 67.73 percent capacity of production respectively.

Out of four selected sugar mills, the capacity utilization rate was relatively better in Indu Shankar Chini Udyog Ltd., Hariwan. However, during FY 1995/96 to FY 2001/2 none of the four sugar mills continuously operated in full capacity.

When we look at the capacity utilization rate of Nepalese sugar industry as a whole, the situation is rather discouraging. It is apparent from Table 2 that the capacity utilization rate of Nepalese sugar industry has been decreasing every year. Table 2 reveals approved total annual capacity of sugar production, actual production and capacity utilization rate of medium and large-scale sugar mills of Nepal from FY 1995/96 to FY 2008/09. The approved production capacity of Nepalese sugar industry was 92826 MT in FY 1995/96 whereas the actual total production of sugar was only 65266 MT. Thus, the capacity utilization rate was 70 percent. Sugar is an essential commodity and Nepal is not self-sufficient in sugar production. So, the policy of Nepalese government should be directed towards encouraging entrepreneurs to invest in this sector. As a result, the approved capacity of production increases due to the establishment of new sugar mills along with the expanded production capacity of existing mills. Despite such 
happenings, the capacity utilization rate was falling every year and it fell down gradually up to 40 percent in FY 2001/02. The capacity utilization rate increased slightly during FY 1999/2000 in comparison to previous fiscal year, but thereafter it showed decreasing trend in FY 2000/01 and FY 2001/02. In FY 2002/03 the production increased up to $100229 \mathrm{MT}$, so the decreasing trend of capacity utilization stopped and it arrived at 43 percent. Thereafter the production of sugar decreased in FY 2003/04 and FY 2004/05 and capacity utilization rate dropped to 42 percent. The production of sugar increased up to 103384 MT in FY 2006/07, which positively contributed to the capacity utilization rate. The increased capacity utilization rate was 45 percent. Due to increase in production quantity, the capacity utilization rate reached to 47 percent in FY 2007/08. In FY 2008/09 the capacity utilization rate fell down to 45 percent. Thus Nepalese sugar industry utilized averagely 48 percent capacity of production during the last 14 years.

Table 2. Approved Total Annual Capacity of Sugar Production, Actual Production and Capacity Utilization rate of Medium and Large Scale Sugar Mills of Nepal form FY 1995/96 to 2008/09

Quantity in $m t$

\begin{tabular}{|l|c|c|c|}
\hline Fiscal Years & $\begin{array}{c}\text { Approved } \\
\text { Production } \\
\text { Capacity of } \\
\text { Sugar (A) }\end{array}$ & $\begin{array}{c}\text { Actual Annual } \\
\text { Production of } \\
\text { Sugar (B) }\end{array}$ & $\begin{array}{c}\text { Capacity } \\
\text { Utilization } \\
\text { (In \%) (B/A X100) }\end{array}$ \\
\hline $1995 / 1996$ & 92826 & 65266 & 70 \\
\hline $1998 / 1997$ & 130226 & 78894 & 61 \\
\hline $1997 / 1998$ & 157426 & 80521 & 51 \\
\hline $1998 / 1999$ & 157426 & 67445 & 43 \\
\hline $1999 / 2000$ & 211275 & 114247 & 54 \\
\hline $2000 / 2001$ & 231669 & 102131 & 44 \\
\hline $2001 / 2002$ & 231669 & 91992 & 40 \\
\hline $2002 / 2003$ & 231669 & 100229 & 43 \\
\hline $2003 / 2004$ & 231669 & 97758 & 42 \\
\hline $2004 / 2005$ & 231669 & 97736 & 42 \\
\hline $2005 / 2006$ & 231669 & 98461 & 45 \\
\hline $2006 / 2007$ & 231669 & 103384 & 47 \\
\hline $2007 / 2008$ & 231669 & 108682 & 45 \\
\hline $2008 / 2009$ & 231669 & 103990 & 48 \\
\hline & Average & & 43 \\
\hline
\end{tabular}

Sources: i. Industrial Statistics 2004/05, Department of Industries, Kathmandu, 2005.

ii. Economic Survey 2006/07, Ministry of Finance, Kathmandu 2007.

iii. Economic Survey 2008/09, Ministry of Finance, Kathmandu 2009.

Note: Actual annual production quantity of sugar is based on the data of first eight months in FY 2008/09. 


\section{CAUSES OF UNDER UTILIZATION OF PRODUCTION CAPACITY}

Nepalese sugar mills have been operating below their production capacity. The following reasons were identified during the study:

(i) Most of the sugar mills have not adopted the system of proper and regular maintenance and overhauling of plant and machinery. As a result, industry faced frequent breakdown, low speed and production stoppage, which in turn reduced the capacity of production immensely.

(ii) Before production season of sugar, sugarcane growers and management of sugar mills used to have conflict about the fixation of minimum support price of sugarcane. Farmers always claimed higher price whereas sugar producers offered lower rate. Some important weeks of crushing season used to pass in hot discussion between them and ultimately government used to interfere and the price of sugarcane used to be settled. This conflict shortened their important production period. Consequently, mills operated for lesser days and crushed lesser sugarcane than the capacity.

(iii) The employees of sugar mills raised various demands just before the commencement of production season and management was engaged in negotiation. Those demands sometimes had to strike and it took time to resolve the problem. As a result, there was delay in sugar production and mills could run minimum days during whole season.

(iv) Nepal has been suffering from political disturbances like strike, blockade, curfew, lockout etc. since last fourteen years, which adversely affected regular supply of sugarcane, into the mills. Thus, in the absence of main raw material (sugarcane) sugar mills remained either closed during season of sugar production or they ran very slowly.

(v) Eleven medium and large-scale sugar mills are registered and approved capacity of production of these mills was 231669 MT during FY 2008/09 but three sugar mills were not in operation. The closed sugar mills were Morang Sugar Mills Ltd., Biratnagar, Mahendra Sugar and General Industries P. Ltd., Bhairahwa and Birgunj Sugar Factory Ltd., Birgunj. Consequently, the capacity utilization of Nepalese sugar industry fell down to 45 percent.

(vi) The government and Nepalese sugar mills have not taken proper care in the promotion of sugarcane farming. The quality of sugarcane was not as per the requirement of sugar industry. Consequently, the productivity (yield) of sugarcane and recovery percentage from sugarcane was also lower i.e. 85 percent on average in comparison to international average of 11 percent. Thus, the quality of raw material was also a cause of lower production and under utilization of production capacity.

(vii) Newly established sugar mills have increased their capacity of production but the production of sugarcane could not be increased at the same rate in their command area. They could not make proper effort 
honestly to increase the yield rate and production of sugarcane significantly. During the production season, sugar mills faced scarcity of sugarcane so they used to procure new material from other sugar mills' command area. This created unhealthy competition among them and finally all sugar mills faced problem in regular and sufficient supply of sugarcane. Further, they were not interested to collect sugarcane from distant areas due to high transportation cost and lesser recovery rate. Sugarcane growing farmers had no market of their produce where sugar mills were not situated. Thus, due to decrease in sucrose content, loss in weight and increase in transportation cost the farmers of distant areas could not supply sugarcane to sugar mills so they operated for fewer days than their target and capacity.

(viii) The neglect of sugar producers decreased the production of sugar as they knew well that low production of sugar would create scarcity in the market. The lower supply would increase the price of sugar in the market and they would be able to earn more profit by selling sugar at higher prices and this situation would enable them to earn more profit without producing higher volume of sugar. This situation discouraged them to utilize maximum capacity of production.

\section{CONCLUSIONS}

Nepalese sugar mills have been operating below the production capacity so they are not meeting national demand of sugar. There is decline in supply of sugar which is fulfilled by imported as well as smuggled sugar from Indo Nepal border. However, the plant and machinery of Nepalese sugar mills are adequate to meet the requirement of domestic market.

Nepalese sugar mills face excessive competition in purchase of sugarcane. In the absence of proper and formal allocation of command area, every sugar mill tries to procure sugarcane from other mills' command area, which ultimately creates unhealthy competition among them. The loser sugar mill faces scarcity of sugarcane and produces less sugar than its capacity. Due to decrease in sucrose content and increase in transportation cost, sugarcane cannot be procured from distant areas where sugar mills are not situated. This situation discourages farmers to grow more sugarcane. Further, the yield rate of sugarcane farming is not satisfactory and the quality of sugarcane is also not good for the production of sugar in comparison to neighboring country India.

The capacity utilization rate of sugar industry decreased continuously and fell down to 45 percent till FY 2008/09. The reasons of under utilization of production capacity are various such as stoppage, frequent break down, slow motion of machines, delay in supply of sugarcane due to non settlement of minimum support price of sugarcane. Similarly, other reasons are sub-standard quality of sugarcane, irregular or less supply of sugarcane, conflict created by employees before commencement of production season, political unrest, less operation days of sugar mills and ultimately the internal neglect of sugar producer to utilize full capacity of production. 


\section{SUGGESTIONS}

The following recommendations can be considered to increase the capacity utilization rate of Nepalese sugar industry:

I. Nepalese sugar mills should try their best to utilize their production capacity fully so that economies of scale can be achieved and total domestic need of sugar can be met. There should be appropriate schedule of repair and maintenance of plant and machinery. The old and obsolete plant and machinery should be replaced and modern technology should be adopted.

II. Both the government and sugar mills should pay major role in promoting the sugarcane farming. The production quantity and quality of sugarcane should be improved. To reduce conflict in collection of sugarcane, proper command area of sugarcane procurement should be fixed formally as per the production capacity of sugar mills.

III. Nepalese sugar producers should try to increase the recovery percentage of sugar from sugarcane and reduce the gap of 2.5 percent lower recovery rate in comparison to international standard. For this purpose, the quality of raw material (sugarcane) and the production process (technique) of sugar should be improved.

IV. The minimum support price of sugarcane should be set at least one month before the commencement of production season of sugar.

V. There is need of clear and appropriate sugar policy on the part of government. The government should promote sugar industry as well as provide various incentives to sugarcane growing farmers. Sugar policy should be focused on solving the problem of high price, low production and scarcity of sugar. The policy should solve the problem of under utilization of production capacity, smuggling of sugar and sugarcane also.

\section{WORKS CITED}

Bajracharya, P. and B. K. Shrestha.1983. Management Problems in Public Sector Manufacturing Enterprises in Nepal. Centre for Economic Development and Administration, Tirbhuvan University, Kathmandu.

Bhagat, S. K. 2008. Marketing of Agro-based Products in Nepal (with special reference to cigarette and sugar). Ph.D. Dissertation, Faculty of Management, Tribhuvan University, Kathmandu.

Bista, N. K. 1985. Agro-based Industries in Nepal: Problems and Prospects. Unpublished research paper, Research Division, Rector's Office, Tribhuvan University, Kathmandu.

Das, A. K. 1989. Marketing of Selected Food-grains and Cash Crops in Nepal. Unpublished Ph.D. Dissertation, Faculty of Commerce, Patna University, India. 
Government of Nepal. 2005. Department of Industries. Industrial Statistics 2004/05. Government of Nepal, Kathmandu.

Government of Nepal. 2007. Agri-Business Promotion and Statistics Division. Statistical Information of Nepalese Agriculture 2006/07. Government of Nepal, Kathmandu.

Government of Nepal. 2007. Ministry of Finance. Economic Survey FY 2006/07. Government of Nepal, Kathmandu.

Government of Nepal. 2008. Central Bureau of Statistics. Nepal in Figures 2008. Government of Nepal, Kathmandu.

Government of Nepal. 2009. Ministry of Finance. Economic Survey FY 2008/09. Government of Nepal, Kathmandu.

Industrial Times. 1976. New High in Capacity Utilization. 18: 24.

Mahto, R.K. 2003. Profit Planning: A Case study of Janakpur Cigarette Factory Ltd. Unpublished Master's thesis, Tribhuvan University, Kathmandu.

Mishra, B.R. 2001. Profit Planning in Manufacturing Company: A Case Study of Vashulinga (DSM) Sugar Mills Ltd. Unpublished Master's thesis, Tribhuvan University, Kathmandu.

Pandey, S.P. 2003. A Study on Profit Planning of Lumbini Sugar Mills Ltd. Unpublished Master's thesis, Tribhuvan University, Kathmandu.

Pradhan, P. 1980. Prospects and Potential of Agro-based Industries in Nepal. Kathmandu.

Regmi, D. 2003. Profit Planning and Control of Sri Ram Sugar Mills Ltd. Unpublished Master's Dissertation, Tribhuvan University, Kathmandu.

Sah, S.S. 1997. Profit Planning in Public and Private Enterprises in Nepal. Unpublished Master's Dissertation, Faculty of Management, Tribhuvan University, Kathmandu.

Sharma, G.R. 1999. Marketing practices in Manufacturing Enterprises in Nepal. Ph.D. Dissertation, Banaras Hindu University.

Shrestha, P.P. 2004. Privatization and Economic Performance: A Study of Selected Privatized Public Enterprises of Nepal. Ph.D. Dissertation, Faculty of Management. Tribhuvan University, Kathmandu.

Srivastava, J.P. 1982. Labor Productivity Socio-economic Dimensions. Oxford and IBH Publishing House Co., New Delhi.

Subedi, B.S. 1978. Problems of Agricultural Marketing in Nepal (with special reference to sugarcane marketing). Unpublished Master's Dissertation, Institute of Humanities and Social Sciences, Tribhuvan University, Kathmandu. 